\title{
GINCANA AMBIENTAL COMO FONTE INSPIRADORA DE PRESERVAÇÃO NA COMUNIDADE FLEXEIRA SITUADA NA RESEX MARINHA DE TRACUATEUA-PA
}

\author{
Dandara Bechara Resque ${ }^{1}$; Neuma Teixeira dos Santos²; Sanae Nogueira Hayashi ${ }^{3}$
}

\section{RESUMO}

Referente a um dos compromissos firmados pela Chamada № 18/2013 $\mathrm{MCTI} / \mathrm{CNPq} / \mathrm{SPM}$-PR/Petrobras - Meninas e Jovens Fazendo Ciências Exatas, Engenharias e Computação, através do projeto Mapeamento Digital do Manguezal na área da Reserva Extrativista Marinha de Tracuateua (RESEX), Nordeste Paraense, a Gincana Ambiental teve como objetivo incentivar alunos da escola Prof Bolivar Bordallo da Silva, situado no município de Bragança, a importância da integração entre ecologia/preservação ambiental e como esta está relacionada aos cuidados provindos do dia-a-dia, além dos conceitos físicos e biológicos discutidos com representantes da RESEX, dentro da comunidade de Flexeira e as relações que uma gincana ambiental, por meio de noções cartográficas, promove para entender os riscos e benefícios de manejo e conservação ambiental.

Palavras-chave: Educação Ambiental; Ecologia; Noções Cartográficas.

\section{ENVIRONMENTAL GYMKHANA AS AN INSPIRING SOURCE OF PRESERVATION IN THE FLEXEIRA COMMUNITY LOCATED IN THE RESEX MARINHA DE TRACUATEUA-PA}

\begin{abstract}
Referring to one of the commitments signed by Call No. 18/2013 MCTI / CNPq / SPM-PR / Petrobras - Girls and Young People Making Exact Sciences, Engineering and Computing, through the Digital Mangrove Mapping Project in the area of the Extractive Marine Reserve of Tracuateua (RESEX), Northeast of Paraense, the Environmental Gymkhana had the objective of encouraging students of the Prof. Bolivar Bordallo da Silva school in the city of Bragança, the importance of the integration between ecology / environmental preservation and how it is related to day-to-day care, besides the physical and biological concepts discussed with representatives of RESEX within the Flexeira

1 Graduada em Engenharia Cartográfica e de Agrimensura. Universidade Federal Rural da Amazônia (UFRA). E-mail: dandararesque@gmail.com.

2 Mestre em Engenharia Elétrica em Energias Renováveis. Docente da Universidade Federal Rural da Amazônia. Líder do Grupo de Pesquisa e Extensão do Laboratório de Geotecnologias, Educação Financeira e Ambiental (LABGEFA). E-mail: neumasantosufra@gmail.com.

3 Mestre em Botânica. Docente da Universidade Federal Rural da Amazônia. Vice-líder do Grupo de Pesquisa e Extensão do Laboratório de Geotecnologias, Educação Financeira e Ambiental (LABGEFA). E-mail: sanaenh@gmail.com.
\end{abstract}


community and the relationships that a environmental gymkhana, through cartographic notions, promotes to understand the risks and benefits of management and environmental conservation.

Keywords: Environmental Education; Ecology; Cartographic Notions.

\section{Introdução}

Gincana é uma palavra de origem indiana e que segundo Felício et al. (2008), é uma atividade de caráter lúdico com propriedades de jogo. É uma ação livre que tem a capacidade de absorver os jogadores em sua totalidade e de modo intenso (HUIZINGA, 2007). Consequentemente, por ser lúdico é possível promover uma metodologia que haja a capacidade de potencializar a prática pedagógica no processo de ensino-aprendizagem de quaisquer tipos de atividades relacionada, como no campo da Educação Ambiental (SANTOS, 2008).

Por sua vez, Educação Ambiental é o método de aprendizagem permanente que considera o respeito a todas as formas de vida, através de valores e ações entre o homem e a sociedade para preservar o equilíbrio do sistema ecológico, com responsabilidade individual e coletiva em níveis: local, nacional e planetário, conforme descrito no Tratado de Educação Ambiental para Sociedade Sustentáveis e Responsabilidade Global (1992).

Assim, o meio ambiente é um direito garantido a todos de forma a ser ecologicamente equilibrada para uso comum, tal como ser essencial a qualidade de vida sadia, depositando na sociedade como dever, a responsabilidade de defender e preserva-lo para as presentes e futuras gerações (CRFB, 1988).

Desse modo, diante do compromisso firmado pelo projeto Mapeamento Digital do Manguezal na área da Reserva Extrativista Marinha de Tracuateua, Nordeste do Estado- PA, a proposta contou com o objetivo principal de traçar um perfil ambiental, econômico e social da situação do manguezal na área da Reserva Extrativista Marinha de Tracuateua, contando com diversas metas, dentre elas, realizar gincana de educação ambiental, através da coleta de resíduos sólidos dentro da área destinada aos mangues, para conscientizar os alunos da escola EEEFM Prof Bolivar Bordallo da Silva - contemplado no projeto e localizado no município de Bragança à aproximadamente $15 \mathrm{~km}$ de 
Tracuateua - a proteger o meio ambiente e reciclar o lixo quando possível, além de estimular a conscientização local.

O município de Tracuateua é situado na Mesorregião do Nordeste Paraense e Microrregião Bragantina, com coordenadas 0046'18" de latitude sul e 47010'35" de longitude oeste de Greenwich, foi emancipada a cerca de 20 de anos separando-se do território de Bragança e tornando-se um município independente (IDESP, 2014). Compreende vários vilarejos dentre eles Vila Fátima, Vila Socorro, Flexeira, Flexal, Santa Clara, Santa Tereza, Cocal, Tatu e Chapada, abrangendo também, áreas destinadas a RESEX, (FADESP, 2016), (Mapa 1).

Mapa 1: Área de Estudo.

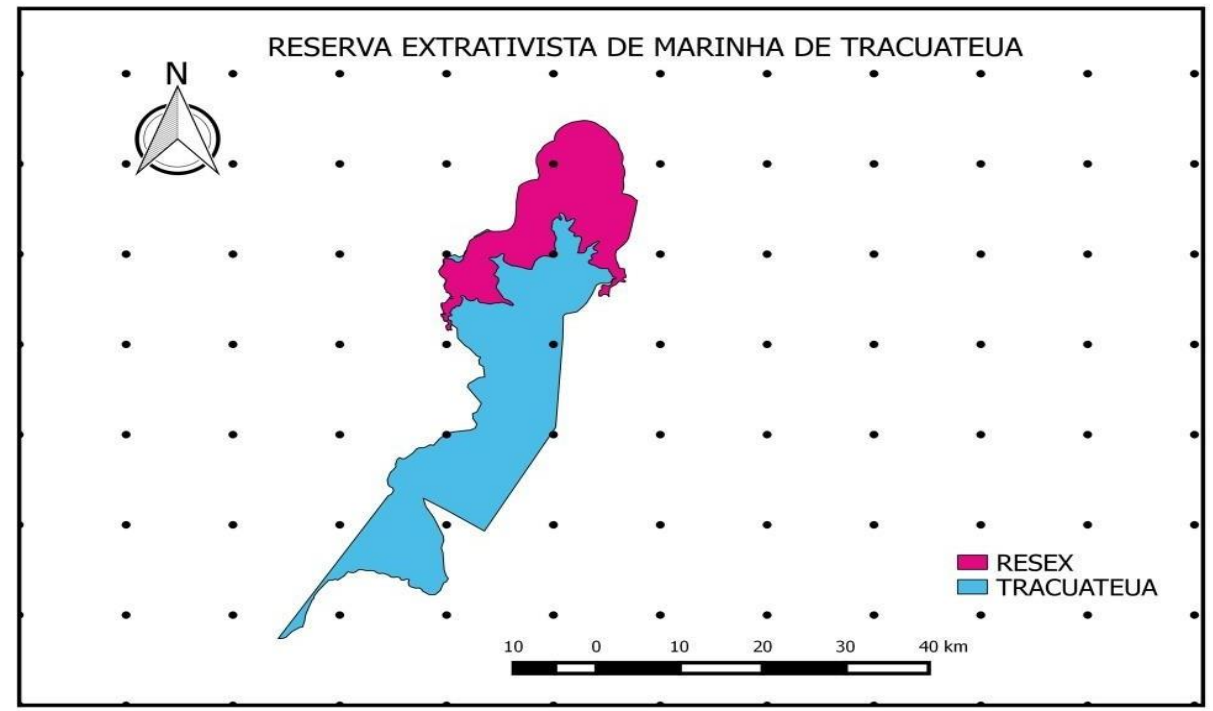

Fonte: Elaborado pelos autores, 2015.

O cenário escolhido foi o vilarejo da comunidade de Flexeira, a qual apresenta maior variação na dinâmica dos mangues e um berçário natural de aves de espécies taquiri e arapapá (Foto 1), observados nas explicações ecológicas e físico-cartográficos realizadas pelos professores: Professor de Biologia da escola do Bordallo, juntamente com os Professores de Ecologia e Física da Universidade Federal Rural da Amazônia (UFRA), enfatizando os estudos a respeito dos mangues: vermelho ou tinteira (Rhizophora mangle), preto ou siriúba (Avicennia germinans) e branco (Laguncularia racemosa), finalizando com as ações referentes ao desenvolvimento da Gincana Ambiental. 
Foto 1: Berçário Natural

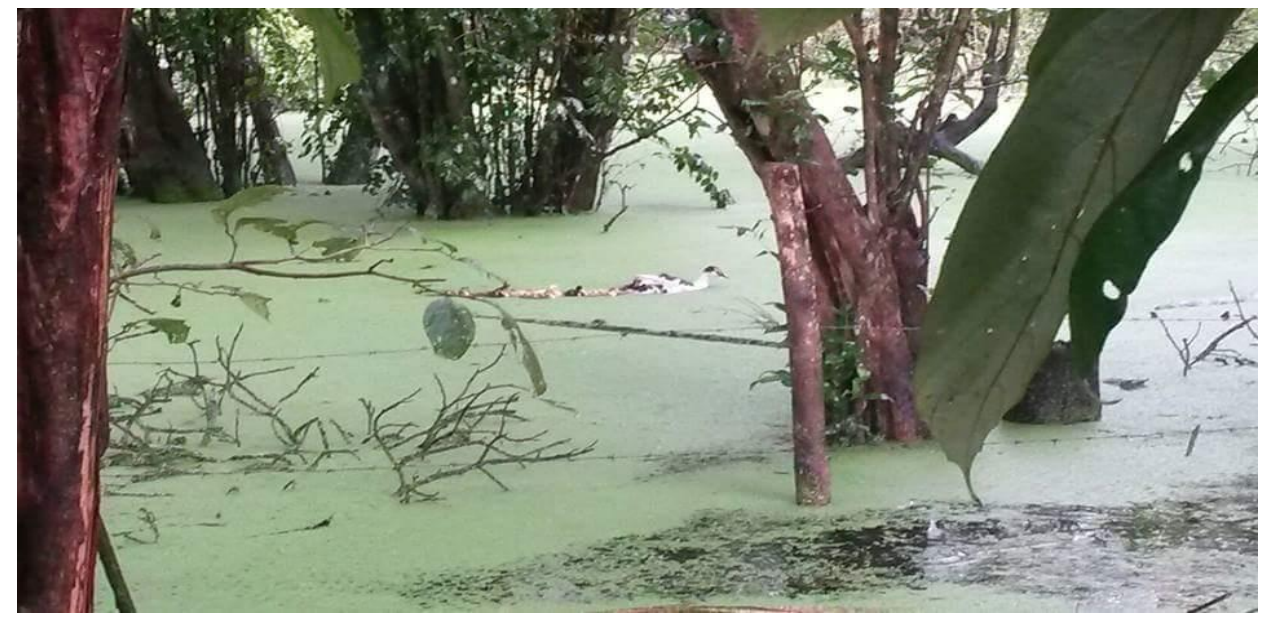

Fonte: Acervo do Projeto, 2015.

A Gincana Ambiental tem a finalidade de estimular e conduzir os participantes a despertá-los as problemáticas relacionadas aos problemas ambientais e sociais não apenas da comunidade local, mas também da comunidade global, sensibilizando-os e conscientizando-os a propor melhorias de qualidade de vida, gerando noção ampla sobre as circunstâncias do pensamento crítico sobre a conscientização e preservação da natureza. Dessa maneira, a participação nas diversas atividades da gincana irá auxiliar os participantes a desenvolverem capacidade suficiente para cumprirem seu papel de cidadania na sociedade e identificar-se como peça chave na busca por um equilíbrio ecológico.

Nesse sentido, surgiram as seguintes perguntas/problemas: Como as atividades previstas, iriam proporcionar a sensibilidade e conscientização dos alunos, comunidade local e demais corpo técnico atuante? Como propor melhorias de qualidade de vida para a população local, envolvendo toda a comunidade para os problemas ambientais e sociais da atualidade?

As próximas seções irão apresentar a metodologia utilizada na realização da gincana com quatro atividades distribuídas por grupos e destacar o relato de experiência vivenciado durante a visita técnica na RESEX.

\section{Metodologia}

A Gincana Ambiental teve quatro ações cada qual com pontuações variadas para incentivar as cinco equipes a conhecer o ambiente, identificando 
a importância da preservação do local.

As Atividades são: Concurso de Paródia, onde os alunos elaboraram letras de músicas com palavras-chaves de caráter obrigatório: Coleta Seletiva, Economizar Água e Reciclagem. Com tempo estimado de 20 minutos para produção.

Criação e Fixação de Placas de Educação Ambiental e Preservação Ambiental: As equipes elaboraram duas placas com materiais recicláveis (placas de madeira) e outros materiais fornecidos como cartolina, lápis, caneta, cola colorida, pincéis e tinta óleo (preta e branca), destacando a criatividade. Com tempo estimado de 20 minutos para produção.

Coleta de Lixo no Local: Nesta atividade os alunos recolheram todos os lixos que conseguiram encontrar nas imediações do Berçário Natural. As pontuações foram distribuídas conforme os tipos de materiais recicláveis: Papel e Papelão: 2 pontos; Vidros, Cristais e Metal; 4 pontos; Plásticos: 6 pontos; Orgânicos: 8 pontos. Com tempo estimado de 20 minutos para a coleta.

Apresentação de Conscientização: As equipes preparam uma apresentação que pontuou de maneira sucinta a vivência no Berçário Natural, destacando como temas: Fauna, Manguezal e Água. Com tempo estimado de 5 minutos para a preparação do material e 5 minutos para a apresentação, utilizando os mesmos materiais da atividade de criação de placas.

\section{Relato de Experiência}

Incluída no roteiro destinado a visita técnica a RESEX, a Gincana Ambiental proporcionou interação entre estudantes do $3^{\circ}$ ano Ensino Médio da Escola Prof Bolivar Bordallo da Silva, estudantes dos $3^{\underline{a}}$ e $4^{\underline{a}}$ etapa do Ensino Fundamental Escola Benjamim Ramos e estudantes de Graduação (Engenharia Cartográfica e de Agrimensura e Ciências Biológicas), juntamente com os coordenadores do projeto, corpo docente e discente da escola pública, responsáveis pela RESEX e comunidade local, com o intuito de oferecer aos alunos o contato direto com a realidade do entorno, principalmente com a valorização e conservação do Berçário Natural, pertencente ao campo Flexeira (Foto 2).

Foto 2: Visita ao manguezal do campo Flexeira. 


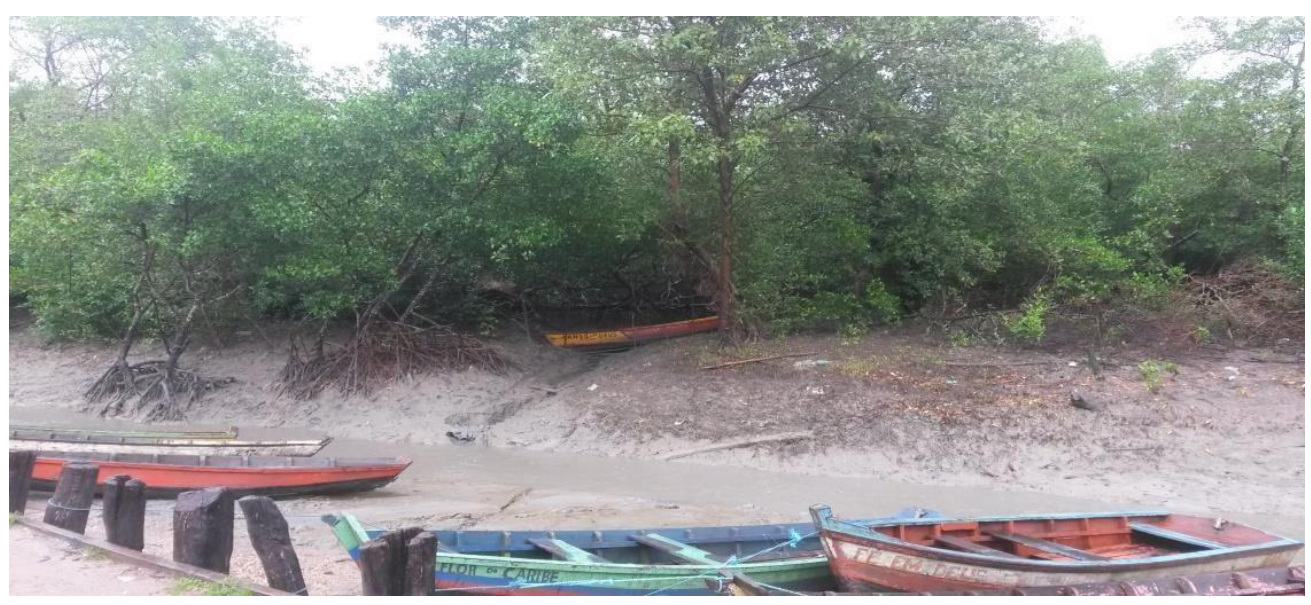

Fonte: Acervo do Projeto, 2015.

Durante o turno da manhã houve um circuito de excursão com palestra que intensificaram os conceitos relativos as atividades da gincana e com um mapa temático em mãos, os alunos se localizaram no ambiente, compreendendo a dimensão espacial do município e o território destinado a comunidade em estudo, além das discussões relacionadas a localização, como manuseio de bússola e estudos de orientação cardeal realizadas no horário da manhã, assim como os estudos envolvendo tipos de mangues e seu processo de desenvolvimento, previsão e conservação ao longo dos anos (Mapa 2).

Mapa 2: Mapa Temático das Comunidades do Município de Tracuateua.

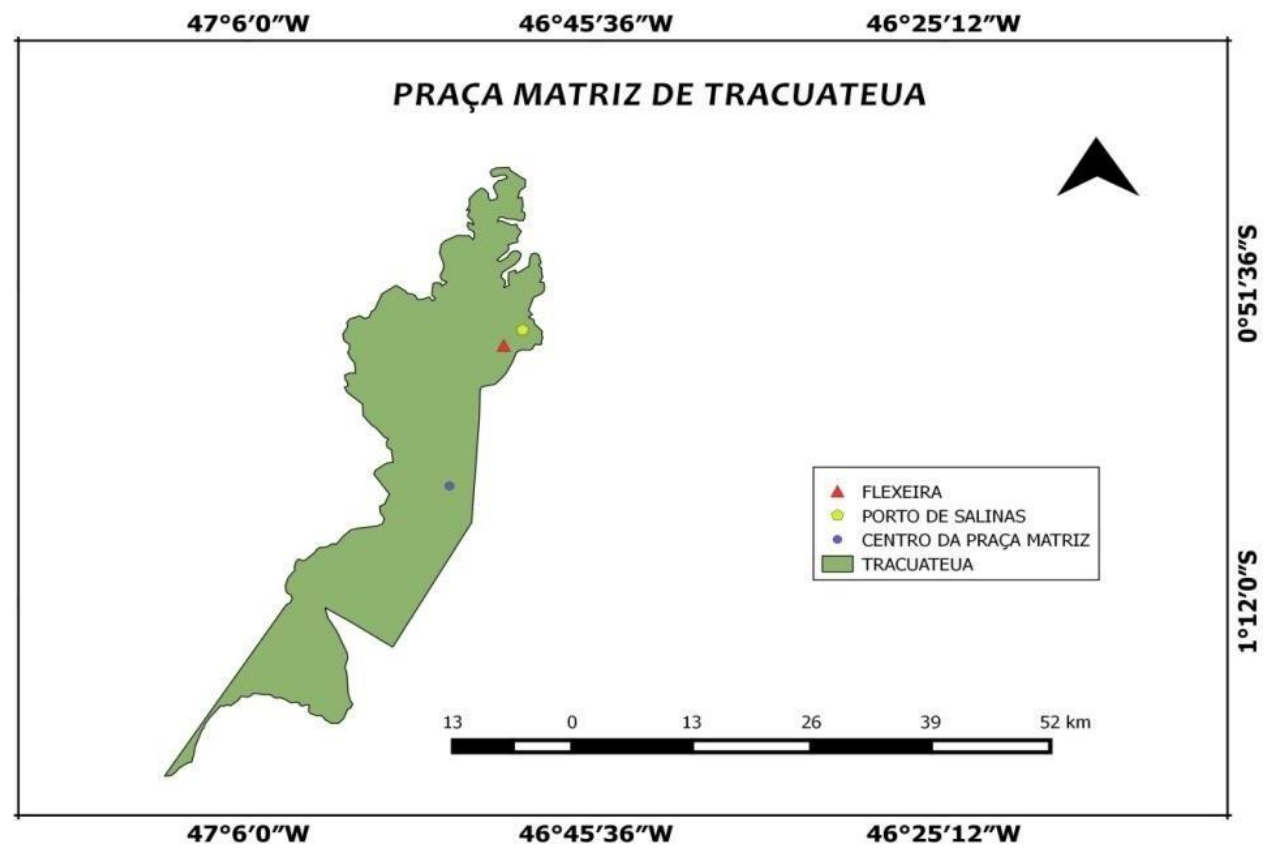

Fonte: Elaborado pelos Autores, 2015.

Uma das explicações sobre a importância da preservação do local veio 
de um dos moradores que vive ao redor da RESEX, enfatizando a conscientização e preservação das áreas de manguezais, fauna, flora e vegetação (Foto 3).

Foto 3: Morador do entorno da RESEX expondo a importância do uso sustentável do manguezal.

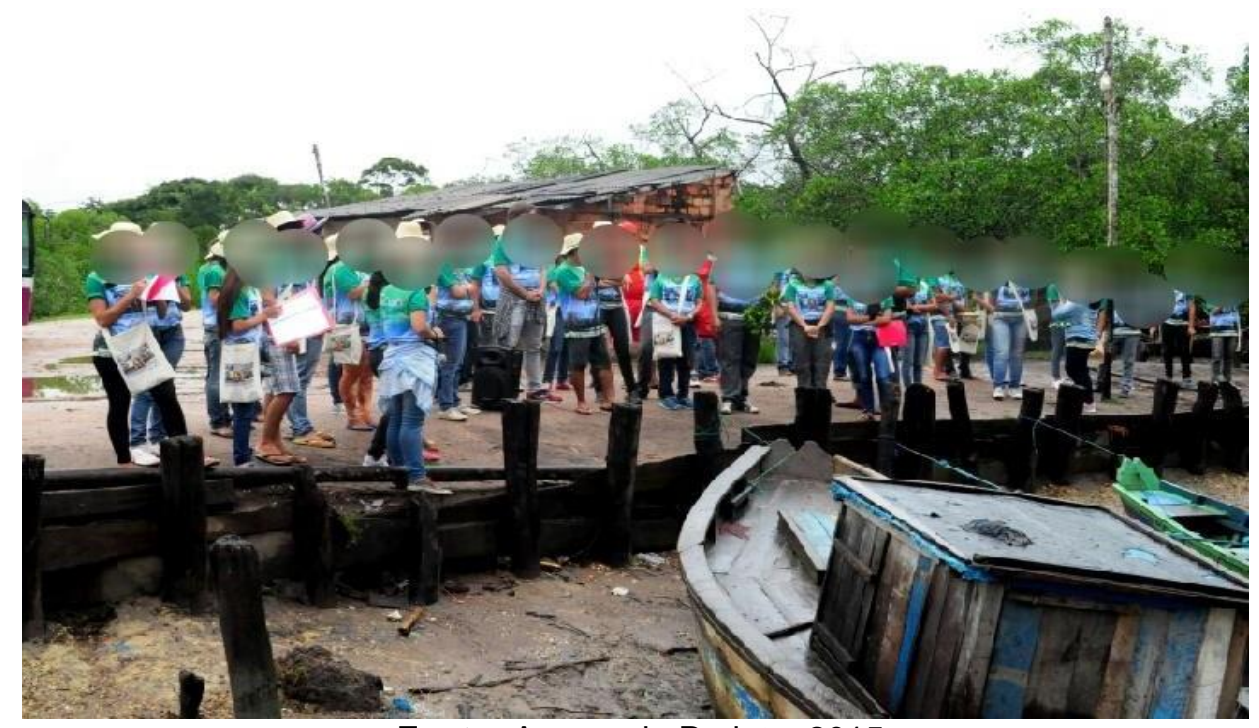

Fonte: Acervo do Projeto, 2015.

Seguindo com as explicações dos Professores de Biologia, a ação dinamizou vários estudos a respeito dos três tipos de mangue: mangue vermelho ou tinteira (Rhizophora mangle), mangue preto ou siriúba (Avicennia germinans) e mangue branco (Laguncularia racemosa), buscando link com área observada (Cocal) e as informações apresentadas na palestra de Ecologia realizada na escola antes da visita em campo, finalizando as ações com a Gincana Ambiental (Foto 4). 
Foto 4: Apresentando os tipos de mangues existentes na região.

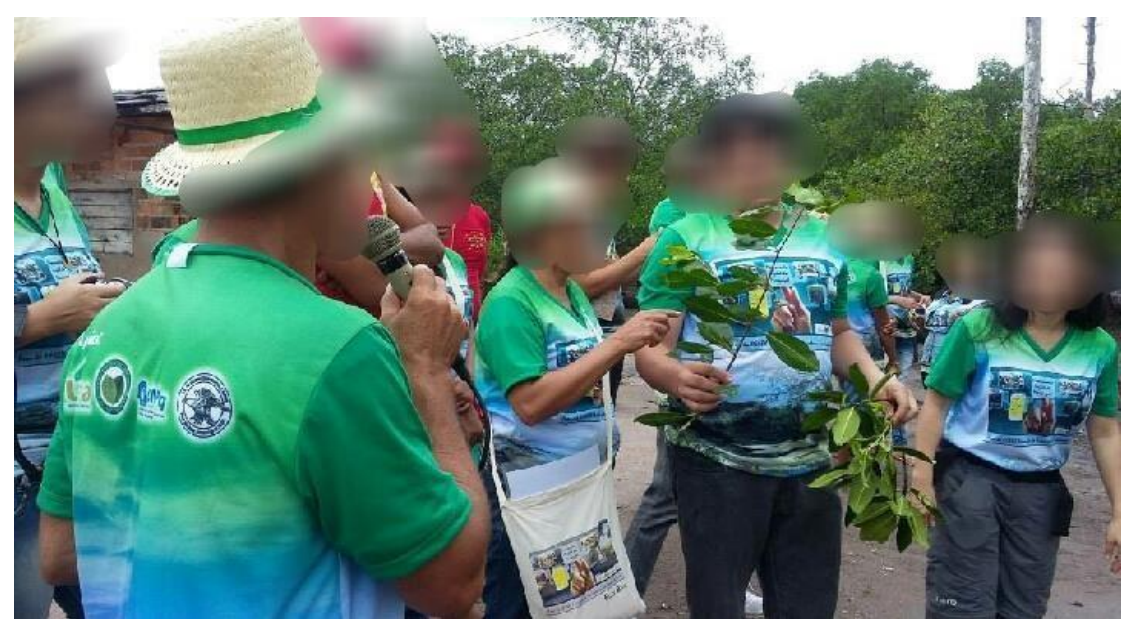

Fonte: Acervo do Projeto, 2015.

Iniciando as 14h00min, a Gincana Ambiental contou com quatro etapas: Concurso de Paródia; Criação e Fixação de Placas de Educação Ambiental e Preservação Ambiental; Coleta de Lixo no Local; Apresentação de Conscientização.

\section{Concurso de Paródia}

Nesta atividade, cada grupo criou e/ou se inspirou em outras músicas para compor letras com as seguintes palavras-chaves, tais quais: coleta seletiva, economizar água e reciclagem. Ao final dos 20 minutos estipulados, o representante de cada equipe iniciou a canção seguindo dos demais. Todas as equipes tiveram pontuação máxima (Foto 5).

Foto 5: Reunião das Equipes.

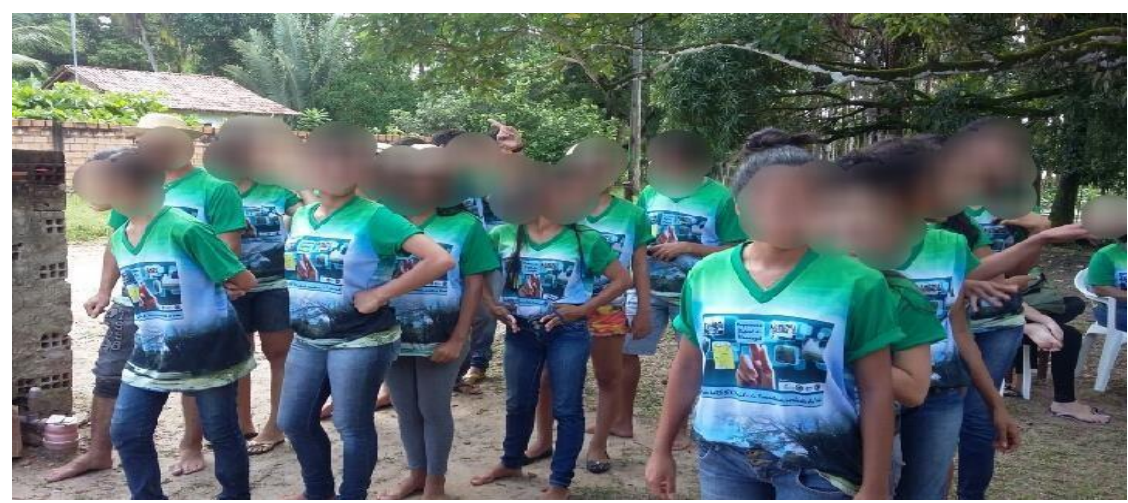

Fonte: Acervo do Projeto, 2015. 


\section{Criação e Fixação de Placas de Educação Ambiental e Preservação Ambiental}

Nesta atividade, cada equipe recebeu os seguintes materiais para criar uma placa sobre a Educação Ambiental e outra sobre Preservação Ambiental: Cartolina; Lápis; Caneta; Cola colorida; Placas de Madeira; Pincel e Tinta Óleo (preta e branca). Lembrando que para pontuar o quesito de maior destaque é a criatividade. Todos os grupos pontuaram com louvor (Foto 6).

Foto 6: Equipe 3 com a placa de fixação.

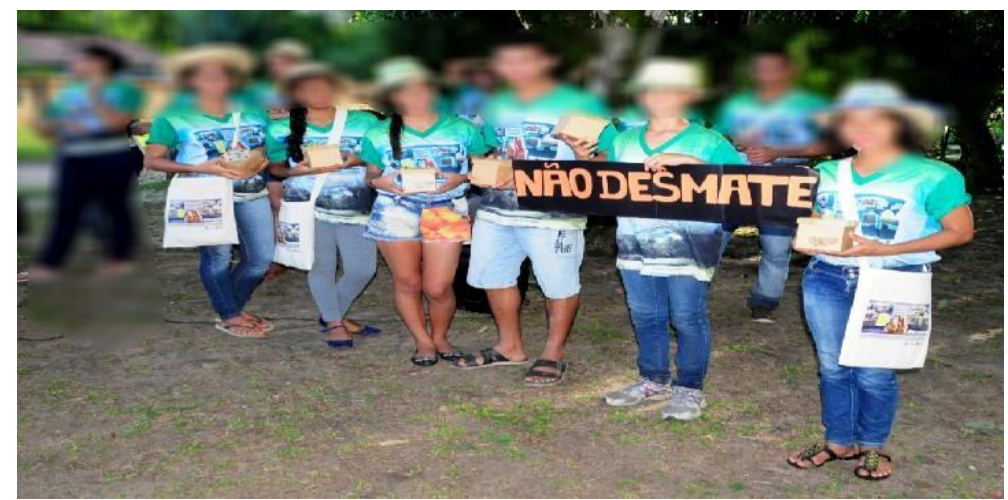

Fonte: Acervo do Projeto, 2015.

\section{Coleta de Lixo no Local}

Ao observar na redondeza do Berçário Natural foi possível notar alguns lixos em seu entorno, dessa maneira esta atividade proporcionou que cada equipe coletasse separadamente cada material de acordo com seu destino reciclável (Foto 7).

Foto 7: Contagem dos materiais coletados.

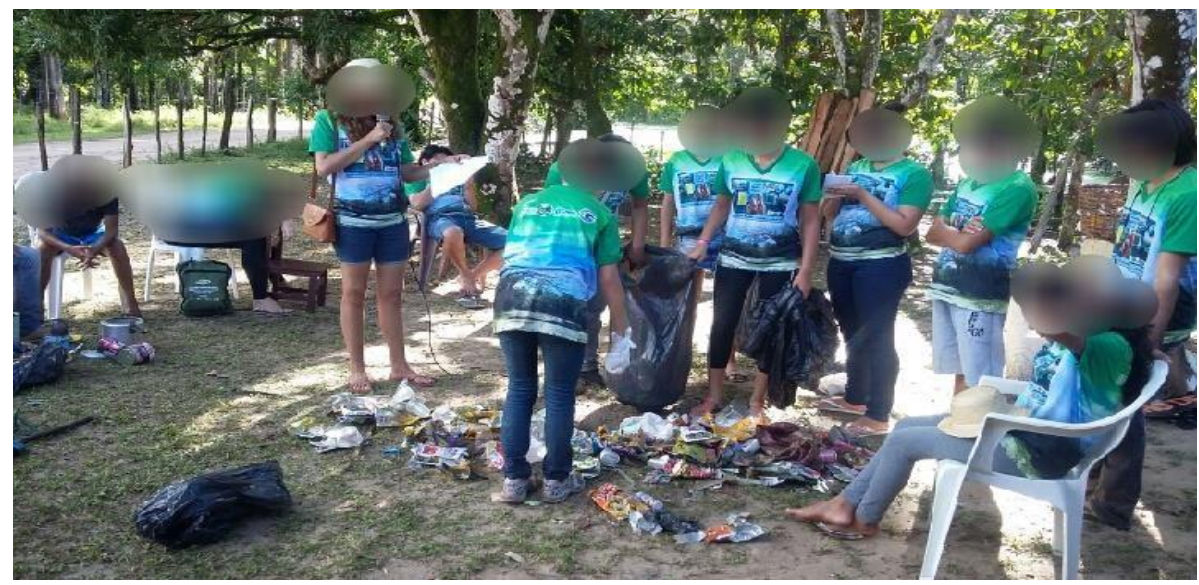

Fonte: Acervo do Projeto, 2015. 
Nenhum dos grupos teve acesso às pontuações distribuídas, todos ficaram livres para recolher os materiais que achassem necessário para a reciclagem. Esta atividade resultou nas seguintes pontuações (Tabela 1):

Tabela 1: Pontuação por equipe.

\begin{tabular}{c|c|c|c|c|c}
\hline $\begin{array}{c}\text { Materiais } \\
\text { Recicláveis }\end{array}$ & Equipe 1 & Equipe 2 & Equipe 3 & Equipe 4 & Equipe 5 \\
\hline $\begin{array}{c}\text { Papel e Papelão } \\
\text { Vidros, Cristais e } \\
\text { Metal }\end{array}$ & $3^{\star} 2=66$ & $26.2=52$ & $30^{\star} 2=60$ & $17^{\star} 2=34$ & $24^{\star} 2=48$ \\
\hline Plásticos & $11^{\star} 6=66$ & $17^{\star} 6=102$ & $14^{*} 6=84$ & $9^{\star} 6=54$ & $9^{*} 6=54$ \\
\hline Orgânicos & $2^{*} 8=16$ & $8^{*} 8=64$ & $3^{*} 8=24$ & $6^{\star} 8=48$ & $1^{\star} 8=8$ \\
\hline Total & 168 & 234 & 188 & 140 & 138 \\
\hline
\end{tabular}

Fonte: Acervo do Projeto, 2015.

\section{Apresentação de Conscientização}

Após todas as atividades, os grupos prepararam uma apresentação sintetizando tudo que foi vivenciado durante a visita não esquecendo de destacar os temas fauna, manguezal e água, com ênfase na conscientização para preservar o local. As equipes utilizaram os mesmos materiais da atividade de criação de placas (Foto 8).

Foto 8: Equipe primeira colocação com o cartaz de conscientização.

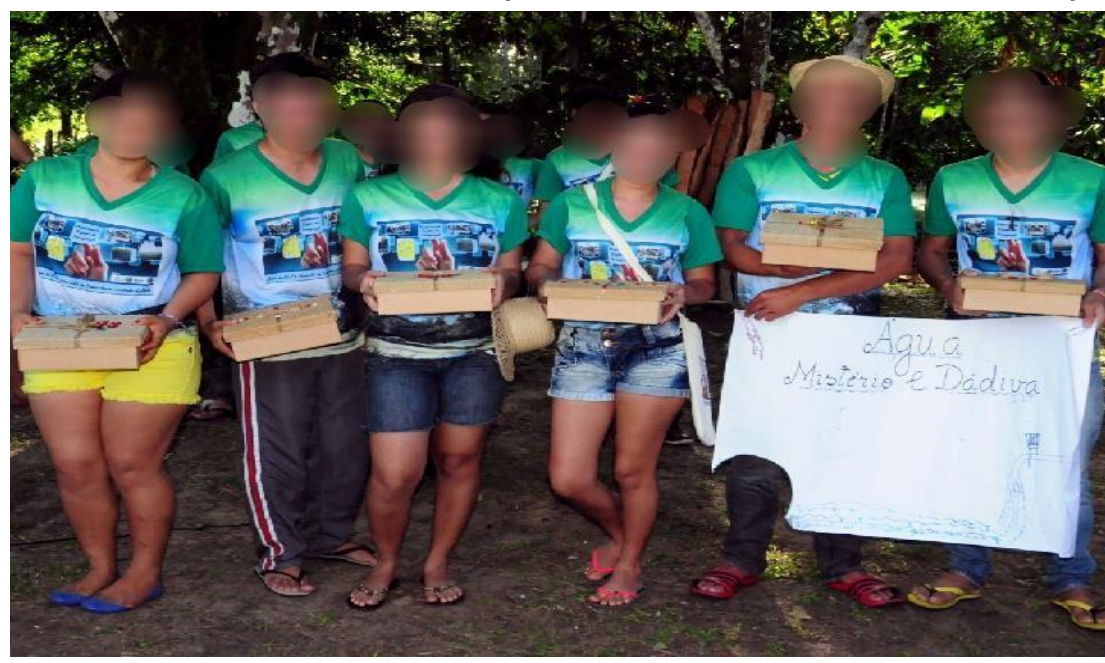

Fonte: Acervo do Projeto, 2015. 


\section{Premiações}

As recompensas dos primeiro e segundo colocados foram confeccionados pelo corpo técnico de todos os envolvidos no projeto.

1ㄴ Lugar: Caixa reciclável feita de papel Paraná, cola e juta de sementes, com 1 mapa múndi, 1 trena, 1 bússola, 1 garrafa térmica e 1 caderno de anotações; 2ㄴ Lugar: Caixa reciclável feita de papel Paraná, cola e juta de sementes, com 1 caderno de anotações, 1 caneta, 1 marca texto, 1 tesoura, 1 cola, 1 grampeador, 1 corretivo e 1 caixa de clips.

Obs: Todos os envolvidos receberam brindes (Sacola Ecobag, Chapéu e Blusa Padronizada do Projeto).

\section{Conclusão}

Considera-se que esta dinâmica, refletiu a valorização do ambiente escolhido, pois evidenciou a importância de reconhecer e enaltecer o meio em que os seres habitam. A gincana proporcionou que todos participassem, obtendo assim, êxito nos objetivos esperados sem grandes dificuldades.

Foi perceptível a interação dentre as equipes a cada atividade concluída, além da relação com demais membros do corpo técnico e comunidade local, deixando de lado o "espírito" competitivo. Dessa forma, a Gincana Ambiental promoveu a reflexão sobre a responsabilidade socioambiental, contribuindo na formação da cidadania, através do comprometimento com o meio ambiente.

Portanto, este tipo de ação é enriquecedor para mobilizar e envolver um ciclo, o ciclo da vida, uma vez que, cuidar do ambiente em que vivemos é cuidar da nossa própria vida e das vidas a serem geradas futuramente.

\section{Agradecimentos}

Os Autores deste trabalho agradecem ao CNPq e a Petrobras pela concessão da Bolsa de Iniciação Científica. Agradecemos a Universidade Federal Rural da Amazônia (UFRA) pela parceria com o Centro Gestor Regional Sistema de Proteção da Amazônia (CENSIPAM), que possibilitou o 
acesso às informações e uso do espaço físico para o desenvolvimento teórico da pesquisa. Agradecemos ao SIPAM Belém pelo uso da estrutura física e por nos disponibilizar o acesso à informação necessária para o desenvolvimento do projeto. E agradecemos a comunidade do entorno da Reserva Extrativista Marinha de Tracuateua (RESEX) por receber de braços abertos esta investigação.

\section{Referências}

BRASIL. Constituição da República Federativa do Brasil. São Paulo: Atlas, 1988.

FElíCIO, C. M.; ElIAS, A. A. A. K.; NASCIMENTO, G. B.; QUEIROZ, C. R. A. A.; PEIXOTO, A. J.; SOARES, M. H. F. B. Gincana lúdica ambiental interdisciplinar: analisando interações e movimentos. Disponível em: http://www.iesa.ufg.br/congea/cong/nupeat TRAB/id0000000000148r0.pdf. Acesso em: 26 ago. 2018.

FUNDAÇÃO AMAZÔNIA DE AMPARO A ESTUDOS E PESQUISAS (FAPESPA). Estatísticas Municipais Paraenses: Tracuateua. Diretoria de Estatística e de Tecnologia e Gestão da Informação. Belém, 2016. 59p. Disponível em: $\quad$ www.parasustentavel.pa.gov.br/wpcontent/uploads/2017/04/Tracuateua.pdf. Acesso em: 15 ago. 2018.

HUIZINGA, J. Homo ludens: o jogo como elemento da cultura. São Paulo: Perspectiva, 2007. In: Gincana lúdica ambiental interdisciplinar: analisando interações e movimentos. Disponível em: http://www.iesa.ufg.br/congea/cong/nupeat TRAB/id000000000000148r0.pdf. Acesso em: 26 ago. 2018.

INSTITUTO DE DESENVOLVIMENTO ECONÔMICO, SOCIAL E AMBIENTAL DO PARÁ - IDESP. Estatística Municipal: Tracuateua. Belém. 2014. 48p. Disponível em: http://fapespa2.pa.gov.br/pdf/estatisticaMunicipal/Tracuateua.pdf. Acesso em: 15 ago. 2015.

SANTOS, S. M. P. A ludicidade como ciência. Petrópolis: Vozes, 2008.

TRATADO DE EDUCAÇÃO AMBIENTAL PARA SOCIEDADES SUSTENTÁVEIS E RESPONSABILIDADE GLOBAL, 1992. Disponível em: www.mma.gov.br/estruturas/educamb/ arquivos/pronea3.pdf. Acesso em: 26 ago. 2018. 